\title{
CARACTERIZACIÓN ARQUEOMÉTRICA DE LA CERÁMICA ÁTICA DEL PALACIO-SANTUARIO DE CANCHO ROANO (ZALAMEA DE LA SERENA, BADAJOZ)
}

\author{
ARCHAEOMETRIC CHARACTERIZATION \\ OF ATTIC POTTERY FROM THE CANCHO ROANO \\ PALACE-SANCTUARY (ZALAMEA \\ DE LA SERENA, BADAJOZ)
}

JAUME BUXEDA I GARRIGÓS (*)

MIGUEL ÁNGEL CAU ONTIVEROS $(* *)$

FRANCISCO GRACIA ALONSO $(* * *)$

\section{RESUMEN}

El conjunto de piezas áticas del palacio-santuario de Cancho Roano (Zalamea de la Serena, Badajoz), con 410 individuos, es uno de los más importantes publicados hasta el presente en la Península Ibérica para el sigloV a.C. Destaca, con 360 piezas, la Copa Cástulo que ofrece una gran variedad morfológica y de características macroscópicas que permiten plantear la hipótesis de la existencia de materiales procedentes de diferentes centros productores. Para contrastar esta posibilidad se ha realizado un estudio arqueométrico por Fluorescencia de Rayos X y Difracción de Rayos X encaminado a la determinación de procedencia de los materiales, así como al estudio de su tecnología de producción. El conjunto caracterizado, con 60 individuos, es el más importante nunca publicado para esta cronología de sigloV a.C. en todo el Mediterráneo. Los resultados sugieren un origen ático, mientras que las grandes diferencias macroscópicas y tipológicas se deben a factores tecnológicos.

(*) Equip de Recerca Arqueomètrica de la Universitat de Barcelona (ERAUB). Dept. Prehistòria, Història Antiga i Arqueologia. Universitat de Barcelona. Baldiri i Reixac, s/n. 08028 Barcelona. Correo electrónico: eraub@ trivium.gh.ub.es.

(**) Department of Archaelogy and Prehistory. University of Sheffield. Northgate House. West Street. S1 4ET Sheffield. United Kingdom. Correo electrónico: m.a.cau@sheffield.ac.uk.

(***) Dept. Prehistòria, Història Antiga i Arqueologia. Universitat de Barcelona. Baldiri i Reixac, s/n. 08028 Barcelona. Correo electrónico: fgracia@trivium.gh.ub.es.

El artículo fue remitido en su versión final el 11-I-99.

\begin{abstract}
The group of 410 attic pots from Cancho Roano palace-sanctuary (Zalamea de la Serena, Badajoz) is considered one of the most important collections of the $5^{\text {th }}$ century $B C$ ever published in the Iberian Peninsula. With 360 examples, the best represented pots are those belonging to the stemless inset-lip type. They show a wide variety in typology and macroscopical features, which suggests the existence of materials from different production centres. Because of this, an archaeometric study by means of X-Ray Fluorescence and X-Ray Diffraction analyses has been conducted in order to investigate their provenance and technology. The characterised material, which includes 60 examples, is the biggest one ever published for the $5^{\text {th }}$ century $B C$ in the Mediterranean basin. The results suggest anAttic origin, while the important differences in their macroscopic and typological features are due to technological factors.
\end{abstract}

Palabras clave: Cerámica ática. Cancho Roano. Arqueometría. Comercio.

Key words: Attic pottery. Cancho Roano. Archaeometry. Trade. 


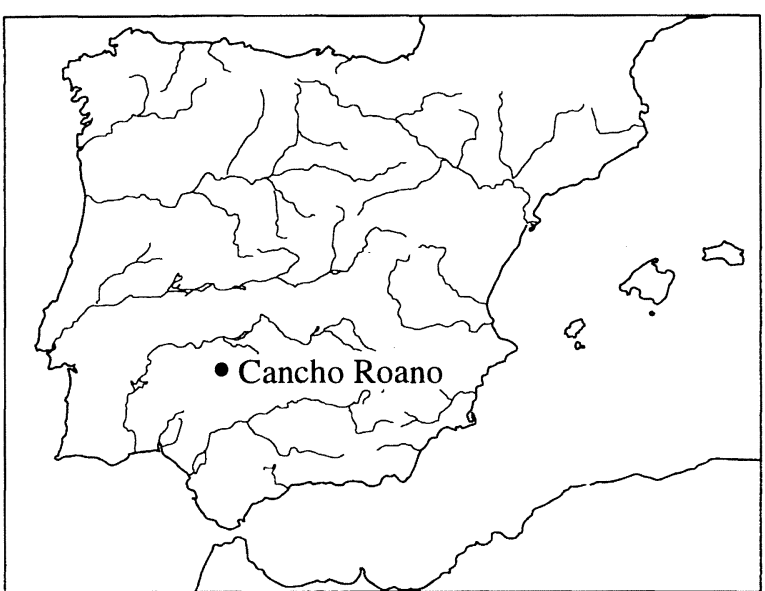

Fig. 1. Localización de Cancho Roano.

\section{INTRODUCCIÓN (1)}

El conjunto de vajilla fina ática del palacio-santuario de Cancho Roano (Fig. 1) conservado en el Museo Arqueológico Provincial de Badajoz (2) (MAPB) procede fundamentalmente del área central del edificio excavado por Maluquer de Motes. Este material presenta una gran y diversa problemática por lo que se refiere al registro arqueológico, y muy especialmente a su distribución en el interior del yacimiento, imposibilitando casi totalmente la formación de conjuntos de piezas, el análisis microespacial y la adscripción estratigráfica. Este último factor, en función de la corta secuencia cronológica del yacimiento (500-400/375 a.C.) y la complejidad de las sucesivas remodelaciones arquitectónicas (fases C-A3) (Celestino y Jiménez, 1993; Celestino, 1996: 335-349), tendría que haber sido clave para analizar tanto el flujo y volumen de materiales, como la cronología de los diversos niveles de ocupación. Las intervenciones realizadas por Celestino desde finales de la década de los ochenta resuelven parcialmente la problemática indicada supra, pero sólo para un grupo muy reducido de ítems y tipos formales.

(1) Trabajo realizado dentro del proyecto "Territorio, estructuras sociales, demografía y concepción del espacio en los asentamientos ibéricos del noreste peninsular" DGICYT PB95-1130, investigador principal: Dr. F. Gracia Alonso.

(2) Agradecemos al Dr. Sebastián Celestino, director del programa de investigación del palacio-santuario de Cancho Roano, las facilidades dadas para la realización de este trabajo. Asimismo agradecemos al Dr. Guillermo Kurtz, director del MAPB la disponibilidad y ayuda en la consulta de los fondos depositados en el museo. Los análisis arqueométricos se han realizado en los Serveis Científico-Tècnics de la Universitat de Barcelona.
Con todo, los individuos de Copa Cástulo, que presentan una alta frecuencia de aparición, ofrecen una amplia variabilidad morfológica y de las características macroscópicas que permiten plantear la hipótesis de la existencia de materiales de diversos centros productores, e incluso de una posible producción local en Cancho Roano o en otro punto de la Península Ibérica. Su identificación y la posibilidad de organización de una secuencia cronológica, facilitaría el estudio pormenorizado de la evolución del yacimiento y de sus interrelaciones comerciales. Así, se procedió al estudio arqueométrico como única metodología capaz de aportar nuevos elementos de evaluación.

\section{ANÁLISIS TIPOLÓGICO}

El conjunto de materiales áticos, formado por 410 individuos, se divide en dos grupos: producciones del estilo de figuras rojas $(5,23 \%)$ y de barniz negro ático $(94,76 \%)$. En el primero predominan las cílicas clase delicada (stemless delicated class) $(3,49 \%)$ sobre los escifos tipo A de Boardman o Richter II $(1,74 \%)$. Por lo que respecta a la cerámica de barniz negro (Gracia, 1994, e.p.), el grupo mayoritario lo constituyen las cílicas de labio cóncavo y moldura interna o Copa Cástulo (stemless inset-lip) (86,27\%) (Gracia, 1994: 178-179). Son minoritarias las copas de borde recto (stemless large plain rim) (4,73\%), las copas de una asa (onehandler black) (1,49\%), los escifos bolsales $(1,24 \%)$, los vasos pequeños (small bowl) $(0,24 \%)$, lékane $(0,48 \%)$ y las lucernas $(0,24 \%)$ (Gracia, 1997).

Con excepción de los trabajos de Blondé (1985, 1989 , e.p.) sobre los materiales de Thasos, la preocupación por la determinación de centros y períodos de fabricación de estas producciones ha sido muy escasa, por lo que las cronologías que se les atribuyen son excesivamente amplias. Éstas son útiles para fechar los niveles de ocupación, pero ineficaces por lo que se refiere a seriar y cuantificar el tráfico mercantil hacia un área geográfica o un asentamiento con un período de vigencia relativamente corto, ya que la coexistencia en un período amplio no significa necesariamente sincronismo ni homogeneidad de distribución, empleo y/o amortización de los diferentes vasos de una misma forma o de las diferentes especies formales. 
Las dos formas de figuras rojas documentadas en Cancho Roano se fechan en el caso de las cílicas entre el 460-375 a.C. y en el de los escifos entre el 450-375 a.C. Del mismo modo, las cerámicas de barniz negro, en función del estudio de Sparkes y Talcott (1970), muestran dos subgrupos. El primero, formado por las copas de borde recto y las lékane, se fecha, según sus horquillas cronológicas respectivas (460-425 a.C. y 450-425 a.C.), en el tercer cuarto del sigloV a.C. El segundo, integrado por las Copa Cástulo, los escifos bolsales y los vasos pequeños, abarca la segunda mitad del sigloV a.C. y el primer cuarto del siglo IV a.C. (450-375 a.C.). Sin embargo, las copas de una asa, también incluidas en este segundo subgrupo, se datan a lo largo de todo el siglo V a.C., aunque en el caso de Cancho Roano y en función de la composición del conjunto cerámico, corresponden a su segunda mitad. Tal restricción no se hace sin problemas, puesto que ante una situación similar en el nivel 16 del Cerro Macareno se llegó a una interpretación diametralmente opuesta, utilizándose las copas de una asa para modificar la cronología de unas Copa Cástulo (Sánchez, 1992: 330).

En este marco, es evidente que intentar realizar una evolución cronológica del flujo de las importaciones a partir tan sólo de las fechas genéricas asignadas a los diversos tipos formales es cuando menos parcial y potencialmente incorrecto. Ello tiende a unificar una problemática compleja en un único período o fase de ocupación cifrada entre los años 450-375 a.C., momento en que se fechan tres remodelaciones (fases A-1, A-2 y A-3) del palacio-santuario de Cancho Roano (Celestino, 1996).

La cronología de los materiales áticos debe obtenerse tomando como base las asociaciones de diferentes tipos de producciones, facilitando la interrelación cronosecuencial entre conjuntos de diferentes yacimientos. Una base para la definición de horizontes o segmentos cronológicos ajustados (Gracia, e.p.) son las asociaciones con las cerámicas del estilo de figuras rojas bien datadas en los siglos V o IV a.C., así como las vicup o los escifos tipo $A$. Pero igualmente, deben tenerse en cuenta también las disociaciones con las copas del Grupo de Viena 116, producción que substituye en cronología y difusión a las Copa Cástulo, como se observa en El Sec (Arribas et alii, 1987). Así, la evolución y variabilidad formal de los tipos deben ser los elementos básicos de estudio.

\section{MORFOLOGÍA DE LAS COPA CÁSTULO}

Las Copa Cástulo de Cancho Roano, con 360 individuos, han sido analizadas formalmente intentando estructurar y definir sus variabilidades intraespecíficas partiendo de los enunciados tipológicos formulados en anteriores trabajos (Gracia, 1994), que permiten determinar tres series principales: serie 1 (cara interior convexa), serie 2 (cara interior recta) y serie 3 (cara interior cóncava). A su vez, las características específicas de fabricación de este tipo formal (modelado separado de la base/pie bajo, cuerpo y asas) condicionan el hecho de que las combinaciones entre perfiles de cuerpo y base sean múltiples, aumentando así las subdivisiones morfológicas por una mayor variabilidad intraespecífi$\mathrm{ca}$, subdividiéndose las series hasta formar un total de 14 subtipos (Fig. 2) (5 en la primera, 8 en la segunda y 1 en la tercera).Además, la decoración del fondo exterior'de los vasos presenta hasta 20 esquemas decorativos diferentes (Fig. 3) y los diámetros de los bordes pueden ser agrupados en 4 categorías distintas (130-159 mm; $160 \mathrm{~mm} ; 161-180 \mathrm{~mm}$; 181-205 mm).
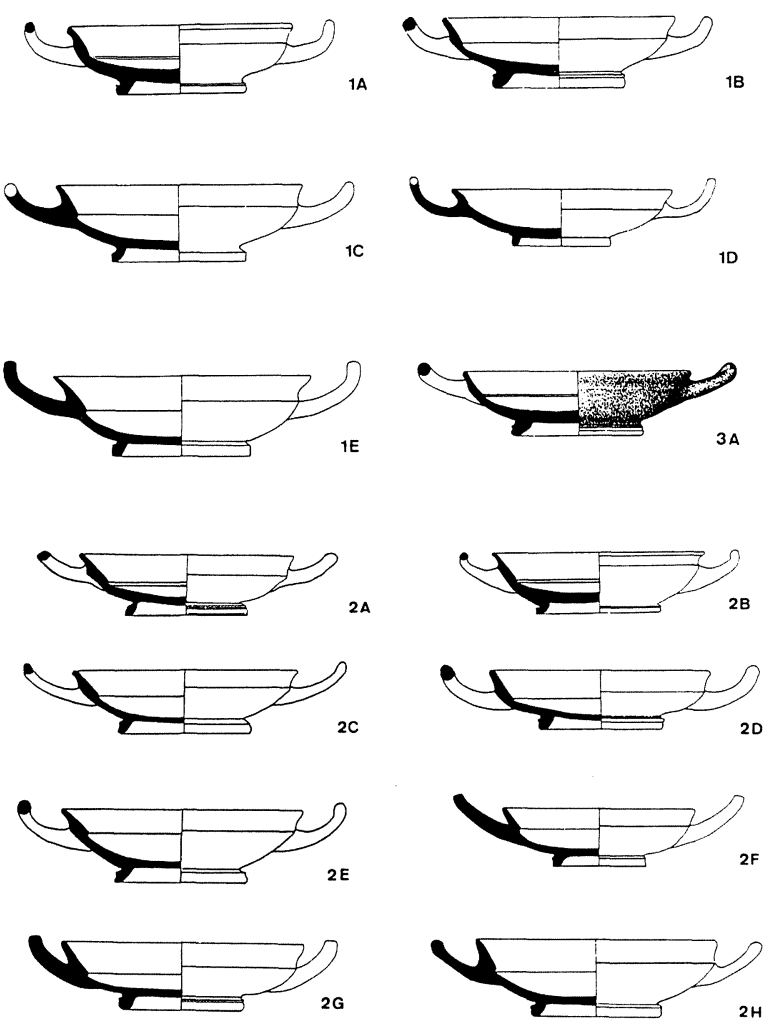

Fig. 2. Tipología de las Copas Cástulo (según Gracia, 1994). 

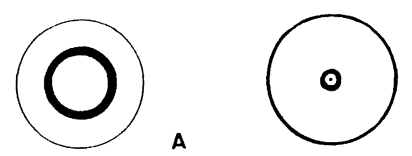

B1

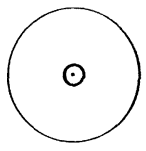

B2
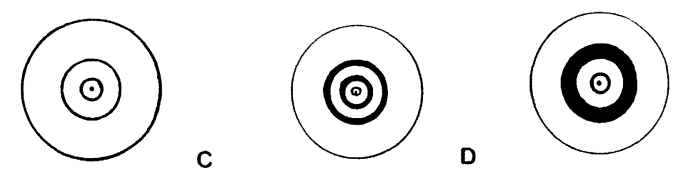

E
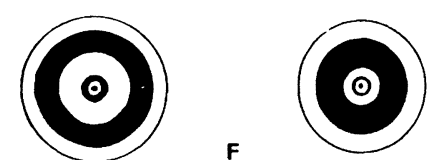

$\mathbf{G}$

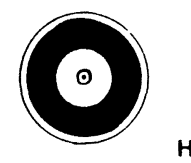

H
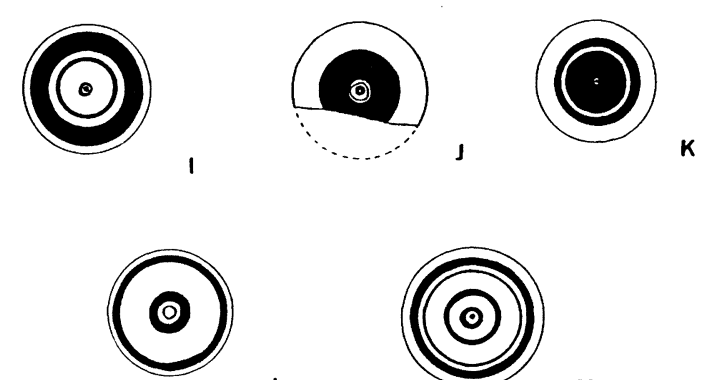

L
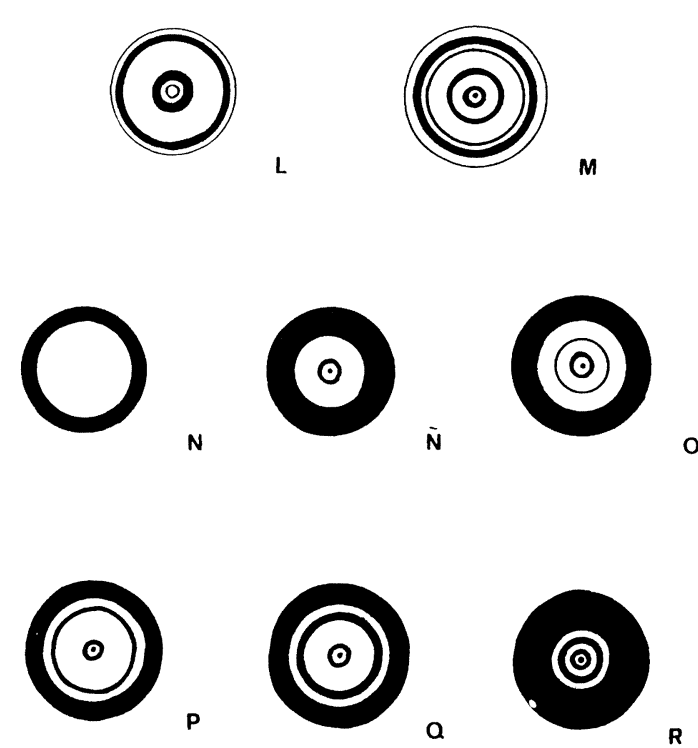

$\odot$

$\mathbf{S}$

Fig. 3. Esquemas decorativos sobre el fondo exterior de la base de las Copas Cástulo (según Gracia, 1994).
Sobre este esquema formal, el conjunto de Copa Cástulo de Cancho Roano, muestra una preeminencia de los vasos de la serie $2(69,42 \%)$ sobre las series $1(32,23 \%)$ y $3(0,41 \%)$. Los subtipos más representados son los $1 \mathrm{~B}(27,27 \%), 2 \mathrm{C}(17,35 \%)$, $2 \mathrm{~F}(16.52 \%)$ y $2 \mathrm{D}(14,04 \%)$ (Fig. 2$)$, agrupando el $75,18 \%$ de estos vasos. Cabe destacar que los subtipos 1B-2D (mayoritarios con un 41,31\%) componen lo que proponemos denominar como Grupo Ibiza (3), que es la serie más representativa del perfil de cílica de pie bajo del período de transición entre los siglos V y IV a.C. por su asociación en yacimientos del Levante y Sudeste a vasos de figuras rojas del estilo de Saint Valentin (Gracia, e.p.).

Partiendo del esquema decorativo del fondo exterior (Fig. 3), se pueden identificar tres grupos básicos que abarcan la mayor parte de los individuos de Cancho Roano. El primero (56,52\%) está formado por las decoraciones del tipo $\mathrm{B}$ (subvariantes B1 y B2), el segundo (17,39\%) por el tipo Ñ y el tercero $(15,21 \%)$ por la serie O-P-Q. Finalmente, los esquemas $\mathrm{C}, \mathrm{F}$ y $\mathrm{S}$ disponen de un número mínimo de ejemplares. Este dato es significativo por cuanto las dos variantes de la serie B corresponden al tipo formal descrito por Sparkes y Talcott (1970: 101-102) a partir del registro del Ágora y puede considerarse por tanto como el esquema decorativo básico de esta producción. Asimismo, los esquemas de la serie B1-B2 son mayoritarios entre los perfiles del Grupo Ibiza. Si atendemos al hecho de que la decoración del fondo exterior puede ser interpretada como una marca de taller, pintor $o$ ceramista tendríamos, según los esquemas decorativos, tres posibles grupos distintos de producción representados en el yacimiento.

El análisis macroscópico de las fábricas (Buxeda et alii, 1995) identifica unas características constantes en toda la producción como son dureza, depuración, compactibilidad y la presencia de desgrasante micáceo en las mismas. No obstante, la coloración no es uniforme como sí lo es, por ejemplo, en las otras producciones de barniz negro ático que configuran el conjunto de vajilla fina ática de Cancho Roano, y cuyas características macroscópicas se aproximan más al concepto clásico de pasta rojiza-anaranjada para la cerámica ática. Los ítems del grupo Copa Cástulo se asocian en tres tipos de fábricas a partir de la coloración de las matrices: Grupo A de fábrica rojiza-anaranjada

(3) La serie $1 \mathrm{~B}-2 \mathrm{D}$ es la mayoritaria entre las piezas de Ibiza conservadas en el Museo Arqueológico Nacional y publicadas por Sánchez (1981). 
$(35,37 \%)$, Grupo B de fábrica ocre $(17,22)$ y Grupo $\mathrm{C}$ de fábrica gris $(42,13 \%)$. Estas diferencias no pueden atribuirse a la acción del fuego durante su amortización en el yacimiento, puesto que sólo una parte muy reducida de los ítems recuperados ( $\mathrm{ca}$. $15 \%$ ) presenta muestras de haberse quemado. Pese a lo que ocurre en otras producciones cerámicas, no puede efectuarse una asociación entre los elementos macroscópicos distintivos de las fábricas, especialmente su coloración, y los tipos formales concretos, al existir en un mismo subtipo fábricas $a$ priori diferentes.

En el análisis de la calidad del barniz y del proceso de fabricación, se constata el carácter masivo y adocenado de esta producción. El barniz presenta múltiples defectos de aplicación, con trazos claros del uso de pincel. En la mayor parte de los vasos está diluido, originando, sobre las superficies exterior e interior de los vasos, diversas variantes de color (negro, marrón-castaño, marrón, rojo coral) y la formación de aguas de tonos múltiples (negro, gris oscuro, azul, azulado-verdoso, verde-oliváceo, marrón), según sea el grado de impregnación de cada punto. El sistema de cocción mediante el apilado de vasos en el interior de los hornos condiciona que el proceso oxidante-reductor-oxidante no afecte por igual a toda la superficie, formándose discos o marcas circulares de color marrón sobre el fondo interior de las cílicas en la zona cubierta por el pie bajo/base del vaso colocado encima. Son también frecuentes las improntas digitales sobre la superficie exterior del vaso y, especialmente, en el pie bajo/base.

Se observan múltiples tipos de defectos de fabricación: improntas digitales realizadas en la arcilla cruda antes de la aplicación del barniz por una manipulación deficiente del vaso, marcas de apilado de vasos, presencia de cúpulas u orificios provocados por reventones durante la cocción, exceso de arcilla en forma de grumos y perfiles deformes por mal modelado. Son asimismo corrientes las marcas de modelado, especialmente los trazos de espatulado y las líneas incisas sobre las diferentes partes de las piezas, como resultado del empleo de instrumentos duros y/o agudos.

Las características morfométricas indican la existencia de diversos tipos de relación entre las variables principales de las mismas (diámetro del borde, diámetro del pie bajo/base y altura). Conclusiones similares han sido constatadas en otros yacimientos (García Martín, 1997: 184). En el caso de la serie 1B-2D, puede apreciarse que los ejem- plares incluidos en los mismos se concentran en las categorías $1(130-159 \mathrm{~mm})(74,41 \%)$ y $2(160 \mathrm{~mm})$ $(25,58 \%)$, siendo inexistentes las piezas con dimensiones pertenecientes a las categorías 3 (161$180 \mathrm{~mm})$ y 4 (181-205 mm). Por formas, el subtipo $1 \mathrm{~B}$ tiene un $75,43 \%$ de piezas en la categoría 1 y un $24,56 \%$ en la 2 . El subtipo $2 \mathrm{D}$ sigue una proporción similar con valores del $70 \%$ y $30 \%$ respectivamente.

Esta diversidad formal, observada y analizada arqueológicamente, además de permitir plantear la existencia de diversos centros de producción, hacen de la Copa Cástulo el objeto idóneo para el subsiguiente estudio arqueométrico.

\section{EL ESTUDIO ARQUEOMÉTRICO DE LAS CERÁMICAS ÁTICAS. ESTADO DE LA CUESTIÓN, MUESTREO Y RUTINA ANALÍTICA}

Desafortunadamente, los avances en la caracterización arqueométrica de las producciones áticas son, hasta el presente, escasos excepto para los aspectos de la tecnología de producción empleada (Jones, 1986; Maniatis et alii, 1993). Los estudios de procedencia son totalmente insuficientes para permitir un conocimiento mínimo de los centros de producción y de sus áreas de difusión y presentan importantes problemas de diseño por centrarse sobre clases cerámicas muy diversas y marcos cronológicos excesivamente amplios (Jones, 1986; Mirti et alii, 1995; Rotuno et alii, 1997). Cabe destacar, sin embargo, el estudio de Fillières et alii (1983) sobre materiales del Ágora de Atenas, que incluye cerámicas procedentes de un horno localizado en la Stoa de Zeus datado en el 430 a.C. Igualmente, son importantes los trabajos de Wolff et alii (1986) sobre vasos de los siglos V y IV a.C. de Cartago, Sicilia, sur de Italia y Atenas, y el proyecto del Laboratoire de Céramologie de Lyon sobre cerámica ática centrado en las producciones de barniz negro del norte de Grecia y el Ática (Blondé, 1985, 1989, e.p.; Picon, 1989).

En Cancho Roano y según la problemática arqueológica planteada anteriormente, el estudio arqueométrico se centró en la caracterización de una muestra aleatoria de 48 individuos de las Copa Cástulo, junto a 12 individuos de otras clases de cerámica ática (Tab. 1). Es importante destacar que el conjunto analizado aquí constituye, para el estudio de las producciones áticas, el más importante 


\begin{tabular}{|c|c|c|c|}
\hline Muestra & Clase & Tipo & $\mathrm{N}^{\circ}$ inventario \\
\hline CR-1 & Cílica & de borde recto & 10532,346 \\
\hline CR-2 & Cílica & de borde recto & 10532,1 \\
\hline CR-3 & Cílica & de borde recto & 10532 \\
\hline CR-4 & Cílica & de borde recto & $10532,279-54$ \\
\hline CR-5 & Cílica & de borde recto & 10532,340 \\
\hline CR-6 & Copa & de una asa & 14411 ZAL 847 \\
\hline CR-7 & Copa & de una asa & 10529 ZAL $817 ;$ ZAL 81,$8 ; 14411 / 3$ \\
\hline CR-8 & Escifos & tipo $\mathrm{A}$ de Boardman & CR90/2; 91,W-2; D.1447 \\
\hline CR-9 & Escifos & tipo $\mathrm{A}$ de Boardman & 10530, ZAL 82 E 10 \\
\hline CR-10 & Escifos & tipo $\mathrm{A}$ de Boardman & 10530 \\
\hline CR-11 & Cílica & clase delicada FR & 10535, ZAL 81,3 E $5 \mathrm{~T}$ \\
\hline CR-12 & Copa Cástulo & 2D fondo exterior $\mathrm{Bl}$ & 10516 ZAL $81 \mathrm{~K} 12$ \\
\hline CR-13 & Copa Cástulo & 2D fondo exterior $\mathrm{B} 1$ & 10523 ZAL 81 E8 K10 \\
\hline CR-14 & Copa Cástulo & 2D fondo exterior $\mathrm{P}$ & $10522 \mathrm{~K} 2$ \\
\hline CR-15 & Copa Cástulo & $2 \mathrm{~A}$ fondo exterior $\hat{\mathrm{N}}$ & $10527 \mathrm{~K} 11141$ \\
\hline CR-16 & Copa Cástulo & 1B & 9377 \\
\hline CR-17 & Copa Cástulo & 1B fondo exterior $\mathrm{B} 1$ & D1446 10 \\
\hline CR-18 & Copa Cástulo & 1B fondo exterior $\hat{N}$ & $10519 \mathrm{~K} 3135$ \\
\hline CR-19 & Copa Cástulo & $2 \mathrm{~F} / 2 \mathrm{D}-2 \mathrm{H}$ fondo exterior $\mathrm{O}$ & D1368 CR 88 \\
\hline CR-20 & Copa Cástulo & 2D fondo exterior $\hat{N}$ & $10520132 \mathrm{~K} 7$ \\
\hline CR-21 & Copa Cástulo & 2D fondo exterior $F$ & $10518131 \mathrm{~K} 6$ ZAL E11 \\
\hline CR-22 & Copa Cástulo & 1B/1C fondo exterior $\mathrm{B} 1$ & $10547 \mathrm{~K} 16$ \\
\hline CR-23 & Copa Cástulo & 2D fondo exterior $\mathrm{BI}$ & $10521138 \mathrm{~K} 4 / \mathrm{K} 8$ \\
\hline CR-24 & Copa Cástulo & $\mathrm{IB} / \mathrm{IC}$ fondo exterior $\mathrm{B} \mid$ & $10515 \mathrm{~K} 8137$ \\
\hline CR-25 & Copa Cástulo & $2 \mathrm{C}$ fondo exterior $\mathrm{P}$ & $10550 \mathrm{~K} 7121$ \\
\hline CR-26 & Copa Cástulo & $2 \mathrm{~F}$ & D1434 \\
\hline CR-27 & Copa Cástulo & $2 \mathrm{H}$ & D1378/1 \\
\hline CR-28 & Copa Cástulo & $2 \mathrm{C}$ & $10545 \mathrm{~K} 1516$ \\
\hline CR-29 & Copa Cástulo & $1 \mathrm{~B} / 1 \mathrm{C}$ & 10549 K69 12419 \\
\hline CR-30 & Cílica & de borde recto & $10552 / 28 \mathrm{~K} 26$ \\
\hline CR-31 & Copa Cástulo & $2 \mathrm{~F} / 2 \mathrm{D}-2 \mathrm{H}$ fondo exterior $\mathrm{N}-\mathrm{S}$ & $10552 / 1 \mathrm{~K} 24$ \\
\hline CR-32 & Copa Cástulo & 1B & $14433 / 6$ \\
\hline CR-33 & Copa Cástulo & $2 \mathrm{~F}$ & $10543 / 17$ \\
\hline CR-34 & Copa Cástulo & $2 \mathrm{D}$ & $10543 / 22$ \\
\hline CR-35 & Copa Cástulo & 1B & 10543 ZAL 78/78 19 \\
\hline CR-36 & Copa Cástulo & $2 \mathrm{E}$ & $10543 / 5$ \\
\hline CR-37 & Copa Cástulo & $2 \mathrm{C}$ & $10541 / 8$ \\
\hline CR-38 & Copa Cástulo & $2 \mathrm{C}$ & 10541/159 ZAL 78-72 \\
\hline CR-39 & Copa Cástulo & $2 \mathrm{C}$ & $10541 / 12$ \\
\hline CR-40 & Copa Cástulo & IB & $10541 / 9$ \\
\hline CR-41 & Copa Cástulo & $2 \mathrm{~A}$ & $10541 / 155$ ZAL 78 \\
\hline CR-42 & Copa Cástulo & $2 \mathrm{D}$ & 10541 ZAL 82 E8 \\
\hline CR-43 & Copa Cástulo & $2 \mathrm{C}$ & $10541 / 3$ \\
\hline CR-44 & Copa Cástulo & $2 \mathrm{C}$ & $10541 / 4$ \\
\hline CR-45 & Copa Cástulo & IB & $10544 / 1 \quad 122$ \\
\hline CR-46 & Copa Cástulo & $2 \mathrm{~A}$ & $10544 / 158 \mathrm{ZAL} 78 / 73$ \\
\hline CR-47 & Copa Cástulo & $2 \mathrm{D}$ & $10544 / 2$ \\
\hline CR-48 & Copa Cástulo & $2 \mathrm{~B}$ & $10544 / 7 \mathrm{C}$ \\
\hline CR-49 & Copa Cástulo & IB & 10544 ZAL 78(70) \\
\hline CR-50 & Copa Cástulo & $2 \mathrm{D}$ & $10543 / 2$ \\
\hline CR-51 & Copa Cástulo & $2 \mathrm{C}$ & $10543 / 8$ \\
\hline CR-52 & Copa Cástulo & 1B & $10543 / 3$ \\
\hline CR-53 & \begin{tabular}{|l|} 
Copa Cástulo \\
\end{tabular} & $2 \mathrm{D}$ & $10543 / 128$ \\
\hline CR-54 & Copa Cástulo & IB & $10543 / 9$ \\
\hline CR-55 & Copa Cástulo & $2 \mathrm{C}$ & $10544 / 7$ \\
\hline CR-56 & Copa Cástulo & $2 \mathrm{D}$ & $10544 / 107$ \\
\hline \begin{tabular}{|l|} 
CR-57 \\
\end{tabular} & \begin{tabular}{|l} 
Copa Cástulo \\
\end{tabular} & $2 \mathrm{C}$ & $10544 / 265$ \\
\hline CR-58 & Copa Cástulo & IB & $10544 / 9$ \\
\hline CR-59 & Copa Cástulo & 1B & $10544 / 129$ \\
\hline CR-60 & Copa Cástulo & $2 \mathrm{E}$ & 10544 ZAL 79/76 \\
\hline
\end{tabular}

Tab. 1. Individuos analizados de Cancho Roano.

considerado hasta el presente para una cronología de, aproximadamente, 450-375 a.C., en todo el Mediterráneo.

La composición química del material se determinó por fluorescencia de rayos $\mathrm{X}$ (FRX) mediante preparaciones de perla (dilución 1/20) y pastilla (Buxeda, 1999), empleando un espectrofotómetro Philips PW 2400, con fuente de Rh, utilizando una recta de calibración configurada con 60 patrones, determinando las concentraciones de: $\mathrm{Fe}_{2} \mathrm{O}_{3}$ (como
Fe total), $\mathrm{Al}_{2} \mathrm{O}_{3}, \mathrm{MnO}, \mathrm{P}_{2} \mathrm{O}_{5}, \mathrm{TiO}_{2}, \mathrm{MgO}, \mathrm{CaO}$, $\mathrm{Na}_{2} \mathrm{O}, \mathrm{K}_{2} \mathrm{O}, \mathrm{SiO}_{2}, \mathrm{Ba}, \mathrm{Rb}, \mathrm{Mo}$, Th, Nb, Pb, Zr, Y, Sr, $\mathrm{Sn}, \mathrm{Ce}, \mathrm{Co}, \mathrm{Ga}, \mathrm{V}, \mathrm{Zn}, \mathrm{W}, \mathrm{Cu}$ y Ni. Igualmente se calculó la pérdida al fuego por calcinación.

La composición mineralógica fue estudiada mediante difracción de rayos X (DRX) utilizando el método de polvo, mediante un difractómetro Siemens D-500, con la radiación $\mathrm{K} \alpha$ del $\mathrm{Cu}(\lambda=1.5406$ $\AA$ ), monocromador de grafito en el haz difractado y una potencia de trabajo de $1.2 \mathrm{~kW}(40 \mathrm{kV}, 30$ $\mathrm{mA}$ ). Las mediciones se realizaron entre 4 y $70^{\circ} 2 \Theta$ con un tamaño de paso de $0.05^{\circ} 2 \Theta$ y un tiempo de $3 \mathrm{~s}$, evaluando los espectros mediante el programa DIFFRAC/AT de Siemens, contando con el banco de datos del Joint Comitee of Powder Diffraction Standars (JCPDS).

\section{COMENTARIO DE LOS RESULTADOS}

Los datos químicos han sido tratados a partir de transformaciones en logaritmos de razón (Aitchinson, 1986, 1992) según

$$
\mathbf{x} \in \mathrm{S}^{d} \rightarrow \mathbf{y}=\log \left(\frac{\mathbf{x}_{-D}}{\mathbf{x}_{D}}\right) \in \mathrm{R}^{d}
$$

donde $\mathbf{x}_{-\mathrm{D}}=\left(\mathrm{x}_{1}, \ldots, \mathrm{x}_{\mathrm{d}}\right)$. La matriz de variación composicional (MVC) se define como

$$
\mathbf{T}=\left[\tau_{\mathrm{ij}}\right]=\left[\operatorname{var}\left\{\log \left(\mathrm{x}_{\mathrm{i}} / \mathrm{x}_{\mathrm{j}}\right)\right\}: \mathrm{i}, \mathrm{j}=1, \ldots, \mathrm{D}\right]
$$

y permite la cuantificación de la variabilidad composicional, expresada por la variación total (vt), asî como la identificación del origen de esta variabilidad composicional y el control de la misma (Buxeda, 1999, e.p.).

La MVC de Cancho Roano (Tab. 2) presenta una vt de 0.610591 que puede considerarse baja (Buxeda y Kilikoglou, e.p.). Es importante destacar la existencia de valores de $\mathrm{vt} / \tau_{\mathrm{i}}$ inferiores a 0.5 $\left(\mathrm{vt} / \tau_{\mathrm{Ba}}=0.433546 ; \mathrm{vt} / \tau_{\mathrm{sr}}=0.361786 ; \mathrm{vt} / \tau_{\mathrm{CaO}}=\right.$ $0.347408 ; \mathrm{vt} / \tau_{\mathrm{Na} 2 \mathrm{O}}=0.300955 ; \mathrm{vt} / \tau_{\mathrm{P} 205}=0.226236$; $\left.\mathrm{vt} / \tau_{\mathrm{Cu}}=0.212574 ; \mathrm{vt} / \tau_{\mathrm{Pb}}=0.164355\right)$ indicativos de las grandes variaciones relativas de tales elementos.

El dendrograma resultante del análisis de agrupamiento sobre la subcomposición $\mathrm{Fe}_{2} \mathrm{O}_{3}, \mathrm{MgO}$, $\mathrm{CaO}, \mathrm{Na}_{2} \mathrm{O}, \mathrm{K}_{2} \mathrm{O}, \mathrm{SiO}_{2}, \mathrm{Y}, \mathrm{Ce}$ y $\mathrm{Ni}$, con el $\mathrm{Al}_{2} \mathrm{O}_{3}$ como divisor en la transformación en logaritmos de razón, se ha realizado con el programa Clustan, utilizando la distancia euclídea al cuadrado media y el algoritmo aglomerativo del centroide (Fig. 4). El dendrograma muestra en la parte inferior todos 


\begin{tabular}{|c|c|c|c|c|c|c|c|c|c|c|c|c|}
\hline MVC & $\mathrm{Fe} 2 \mathrm{O} 3$ & $\mathrm{Al} 2 \mathrm{O} 3$ & $\mathrm{MnO}$ & $\mathrm{P} 2 \mathrm{O} 5$ & $\mathrm{TiO} 2$ & $\mathrm{MgO}$ & $\mathrm{CaO}$ & $\mathrm{Na} 2 \mathrm{O}$ & $\mathrm{K} 2 \mathrm{O}$ & $\mathrm{SiO} 2$ & $\mathrm{Ba}$ & $\mathrm{Rb}$ \\
\hline $\mathrm{Fe} 2 \mathrm{O} 3$ & 0 & 0.000335 & 0.012006 & 0.104787 & 0.002354 & 0.009261 & 0.0575 & 0.056528 & 0.003263 & 0.003045 & 0.0477 & 0.0041 \\
\hline $\mathrm{Al} 2 \mathrm{O} 3$ & 0.000335 & 0 & 0.011973 & 0.104988 & 0.001925 & 0.009363 & 0.06118 & 0.056708 & 0.003594 & 0.003133 & 0.04877 & 0.004615 \\
\hline $\mathrm{MnO}$ & 0.012006 & 0.011973 & 0 & 0.118612 & 0.017822 & 0.02919 & 0.069329 & 0.095653 & 0.017885 & 0.020391 & 0.04751 & 0.016261 \\
\hline P2O5 & 0.104787 & 0.104988 & 0.118612 & 0 & 0.109526 & 0.120728 & 0.148228 & 0.183143 & 0.113965 & 0.112539 & 0.055066 & 0.12075 \\
\hline $\mathrm{TiO} 2$ & 0.002354 & 0.001925 & 0.017822 & 0.109526 & 0 & 0.00997 & 0.064543 & 0.05092 & 0.004375 & 0.002205 & 0.0531 & 0.005334 \\
\hline $\mathrm{MgO}$ & 0.009261 & 0.009363 & 0.02919 & 0.120728 & 0.00997 & 0 & 0.047538 & 0.047151 & 0.015221 & 0.011 & 0.066695 & 0.01438 \\
\hline $\mathrm{CaO}$ & 0.0575 & 0.06118 & 0.069329 & 0.148228 & 0.064543 & 0.047538 & 0 & 0.119031 & 0.071902 & 0.0676 & 0.075775 & 0.06081 \\
\hline $\mathrm{Na} 2 \mathrm{O}$ & 0.056528 & 0.056708 & 0.095653 & 0.183143 & 0.05092 & 0.047151 & 0.119031 & 0 & 0.055799 & 0.042432 & 0.137141 & 0.059092 \\
\hline $\mathrm{K} 2 \mathrm{O}$ & 0.003263 & 0.003594 & 0.017885 & 0.113965 & 0.004375 & 0.015221 & 0.071902 & 0.055799 & 0 & 0.003756 & 0.056276 & 0.004342 \\
\hline $\mathrm{SiO} 2$ & 0.003045 & 0.003133 & 0.020391 & 0.112539 & 0.002205 & 0.011 & 0.0676 & 0.042432 & 0.003756 & 0 & 0.05655 & 0.006184 \\
\hline $\mathrm{Ba}$ & 0.0477 & 0.04877 & 0.04751 & 0.055066 & 0.0531 & 0.066695 & 0.075775 & 0.137141 & 0.056276 & 0.05655 & 0 & 0.048643 \\
\hline $\mathrm{Rb}$ & 0.0041 & 0.004615 & 0.016261 & 0.12075 & 0.005334 & 0.01438 & 0.06081 & 0.059092 & 0.004342 & 0.006184 & 0.048643 & 0 \\
\hline Th & 0.004502 & 0.004074 & 0.019107 & 0.122973 & 0.004743 & 0.012554 & 0.074163 & 0.058409 & 0.007365 & 0.00607 & 0.060478 & 0.007453 \\
\hline $\mathrm{Nb}$ & 0.003746 & 0.004064 & 0.019884 & 0.105813 & 0.003717 & 0.01006 & 0.057273 & 0.050962 & 0.005013 & 0.003319 & 0.045117 & 0.003113 \\
\hline $\mathrm{Pb}$ & 0.15122 & 0.152785 & 0.162237 & 0.095634 & 0.159278 & 0.169953 & 0.184266 & 0.243918 & 0.169376 & 0.168208 & 0.099341 & 0.162955 \\
\hline $\mathrm{Zr}$ & 0.007784 & 0.00798 & 0.029267 & 0.111332 & 0.005751 & 0.011694 & 0.06572 & 0.04178 & 0.008215 & 0.003336 & 0.052974 & 0.006551 \\
\hline $\mathrm{Y}$ & 0.010596 & 0.011 & 0.031466 & 0.101476 & 0.010455 & 0.008853 & 0.045897 & 0.050532 & 0.013494 & 0.010555 & 0.045652 & 0.009001 \\
\hline $\mathrm{Sr}$ & 0.060061 & 0.063263 & 0.079027 & 0.132782 & 0.06386 & 0.055888 & 0.028746 & 0.103795 & 0.065149 & 0.062429 & 0.064033 & 0.05246 \\
\hline $\mathrm{Ce}$ & 0.025238 & 0.024455 & 0.039876 & 0.106179 & 0.025679 & 0.029292 & 0.081247 & 0.08342 & 0.027117 & 0.026136 & 0.047517 & 0.023427 \\
\hline $\mathrm{Ga}$ & 0.003962 & 0.003757 & 0.015959 & 0.101307 & 0.005892 & 0.01132 & 0.056963 & 0.066196 & 0.008095 & 0.008904 & 0.03972 & 0.003777 \\
\hline V & 0.003312 & 0.002732 & 0.016293 & 0.100298 & 0.004276 & 0.011599 & 0.065297 & 0.056257 & 0.006284 & 0.005563 & 0.048659 & 0.008838 \\
\hline $\mathrm{Zn}$ & 0.005104 & 0.004842 & 0.019076 & 0.101419 & 0.006106 & 0.009977 & 0.05484 & 0.066472 & 0.0096 & 0.008977 & 0.043465 & 0.006623 \\
\hline $\mathrm{Cu}$ & 0.099938 & 0.100245 & 0.089377 & 0.213395 & 0.106581 & 0.116704 & 0.14356 & 0.232166 & 0.108217 & 0.116702 & 0.120119 & 0.092718 \\
\hline $\mathrm{Ni}$ & 0.004055 & 0.004366 & 0.010588 & 0.113967 & 0.006793 & 0.013027 & 0.056156 & 0.071345 & 0.008407 & 0.010301 & 0.048064 & 0.004033 \\
\hline$\tau . \mathrm{i}$ & 0.6804 & 0.690144 & 0.988791 & 2.698908 & 0.725205 & 0.841417 & 1.757562 & 2.028849 & 0.786709 & 0.759334 & 1.408367 & 0.72546 \\
\hline$v t / \tau . i$ & 0.8974 & 0.88473 & 0.617513 & 0.226236 & 0.841957 & 0.72567 & 0.347408 & 0.300955 & 0.776134 & 0.804114 & 0.433546 & 0.841661 \\
\hline \multirow[t]{2}{*}{$r v, \tau$} & 0.992429 & 0.990997 & 0.97325 & 0.430436 & 0.988439 & 0.977884 & 0.896839 & 0.967587 & 0.987865 & 0.982454 & 0.727802 & 0.987125 \\
\hline & Th & $\mathrm{Nb}$ & $\mathrm{Pb}$ & $\mathrm{Zr}$ & $\mathrm{Y}$ & $\mathrm{Sr}$ & $\mathrm{C}$ & $\mathrm{Ga}$ & $\mathrm{V}$ & $\mathrm{Zr}$ & $\mathrm{Cu}$ & $\mathrm{Ni}$ \\
\hline $\mathrm{Fe} 2 \mathrm{O} 3$ & 0.004502 & 0.003746 & 0.15122 & 0.007784 & 0.010596 & 0.060061 & 0.025238 & 0.003962 & 0.003312 & 0.005104 & 0.099938 & 0.004055 \\
\hline $\mathrm{Al} 2 \mathrm{O} 3$ & 0.004074 & 0.004064 & 0.152785 & 0.00798 & 0.011 & 0.063263 & 0.024455 & 0.003757 & 0.002732 & 0.004842 & 0.100245 & 0.004366 \\
\hline $\mathrm{MnO}$ & 0.019107 & 0.019884 & 0.162237 & 0.029267 & 0.031466 & 0.079027 & 0.039876 & 0.015959 & 0.016293 & 0.019076 & 0.089377 & 0.010588 \\
\hline P2OS & 0.122973 & 0.105813 & 0.095634 & 0.111332 & 0.101476 & 0.132782 & 0.106179 & 0.101307 & 0.100298 & 0.101419 & 0.213395 & 0.113967 \\
\hline $\mathrm{TiO} 2$ & 0.004743 & 0.003717 & 0.159278 & 0.005751 & 0.010455 & 0.06386 & 0.025679 & 0.005892 & 0.004276 & 0.006106 & 0.106581 & 0.006793 \\
\hline $\mathrm{MgO}$ & 0.012554 & 0.01006 & 0.169953 & 0.011694 & 0.008853 & 0.055888 & 0.029292 & 0.01132 & 0.011599 & 0.009977 & 0.116704 & 0.013027 \\
\hline $\mathrm{CaO}$ & 0.074163 & 0.057273 & 0.184266 & 0.06572 & 0.045897 & 0.028746 & 0.081247 & 0.056963 & 0.065297 & 0.05484 & 0.14356 & 0.056156 \\
\hline $\mathrm{Na} 2 \mathrm{O}$ & 0.058409 & 0.050962 & 0.243918 & 0.04178 & 0.050532 & 0.103795 & 0.08342 & 0.066196 & 0.056257 & 0.066472 & 0.232166 & 0.071345 \\
\hline $\mathrm{K} 2 \mathrm{O}$ & 0.007365 & 0.005013 & 0.169376 & 0.008215 & 0.013494 & 0.065149 & 0.027117 & 0.008095 & 0.006284 & 0.0096 & 0.108217 & 0.008407 \\
\hline $\mathrm{SiO} 2$ & 0.00607 & 0.003319 & 0.168208 & 0.003336 & 0.010555 & 0.062429 & 0.026136 & 0.008904 & 0.005563 & 0.008977 & 0.116702 & 0.010301 \\
\hline $\mathrm{Ba}$ & 0.060478 & 0.045117 & 0.099341 & 0.052974 & 0.045652 & 0.064033 & 0.047517 & 0.03972 & 0.048659 & 0.043465 & 0.120119 & 0.048064 \\
\hline $\mathrm{Rb}$ & 0.007453 & 0.003113 & 0.162955 & 0.006551 & 0.009001 & 0.05246 & 0.023427 & 0.003777 & 0.008838 & 0.006623 & 0.092718 & 0.004033 \\
\hline Th & 0 & 0.007319 & 0.162576 & 0.010067 & 0.015309 & 0.080112 & 0.030846 & 0.007178 & 0.006729 & 0.008166 & 0.099586 & 0.007565 \\
\hline $\mathrm{Nb}$ & 0.007319 & 0 & 0.155791 & 0.002686 & 0.004794 & 0.049293 & 0.022359 & 0.004624 & 0.00699 & 0.005167 & 0.103956 & 0.006385 \\
\hline $\mathrm{Pb}$ & 0.162576 & 0.155791 & 0 & 0.167482 & 0.15137 & 0.169979 & 0.166035 & 0.138142 & 0.152225 & 0.138982 & 0.239672 & 0.153643 \\
\hline $\mathrm{Zr}$ & 0.010067 & 0.002686 & 0.167482 & 0 & 0.005303 & 0.051004 & 0.021674 & 0.008894 & 0.010525 & 0.009273 & 0.1178 & 0.012693 \\
\hline $\mathrm{Y}$ & 0.015309 & 0.004794 & 0.15137 & 0.005303 & 0 & 0.036112 & 0.021112 & 0.007693 & 0.013263 & 0.007966 & 0.115006 & 0.012739 \\
\hline $\mathrm{Sr}$ & 0.080112 & 0.049293 & 0.169979 & 0.051004 & 0.036112 & 0 & 0.064367 & 0.055246 & 0.068922 & 0.056399 & 0.164691 & 0.060098 \\
\hline $\mathrm{Ce}$ & 0.030846 & 0.022359 & 0.166035 & 0.021674 & 0.021112 & 0.064367 & 0 & 0.021495 & 0.028845 & 0.022298 & 0.114629 & 0.027566 \\
\hline $\mathrm{Ga}$ & 0.007178 & 0.004624 & 0.138142 & 0.008894 & 0.007693 & 0.055246 & 0.021495 & 0 & 0.006187 & 0.002801 & 0.09049 & 0.003848 \\
\hline v & 0.006729 & 0.00699 & 0.152225 & 0.010525 & 0.013263 & 0.068922 & 0.028845 & 0.006187 & 0 & 0.008386 & 0.115984 & 0.009319 \\
\hline $\mathrm{Zn}$ & 0.008166 & 0.005167 & 0.138982 & 0.009273 & 0.007966 & 0.056399 & 0.022298 & 0.002801 & 0.008386 & 0 & 0.087628 & 0.006044 \\
\hline $\mathrm{Cu}$ & 0.099586 & 0.103956 & 0.239672 & 0.1178 & 0.115006 & 0.164691 & 0.114629 & 0.09049 & 0.115984 & 0.087628 & 0 & 0.08321 \\
\hline $\mathrm{Ni}$ & 0.007565 & 0.006385 & 0.153643 & 0.012693 & 0.012739 & 0.060098 & 0.027566 & 0.003848 & 0.009319 & 0.006044 & 0.08321 & 0 \\
\hline$\tau . i$ & 0.817342 & 0.681444 & 5069 & 785 & 643 & 1.6 & 807 & & & 9609 & 2.872374 & 0.734212 \\
\hline$v t / \tau . i$ & 0.747045 & 0.896026 & 0.164355 & 0.793197 & 0.825522 & 0.361786 & 0.56494 & 0.908013 & 0.806823 & 0.885417 & 0.212574 & 0.831628 \\
\hline$r v, \tau$. & 0.97798 & 0.993338 & 0.298879 & 0.982187 & 0.983684 & 0.870647 & 0.99373 & 0.995335 & 0.990425 & 0.993956 & 0.916735 & 0.983858 \\
\hline$\Sigma \tau . \mathrm{i}$ & 29.308 & & & & & & & & & & & \\
\hline & 0.610591 & & & & & & & & & & & \\
\hline
\end{tabular}

Tab. 2. Matriz de variación composicional (MVC) de los individuos de Cancho Roano.

los individuos analizados que se van uniendo hasta formar un único grupo, a la distancia ultramétrica indicada en la escala de la izquierda. Cuanto mayor es la distancia ultramétrica de una fusión mayor es la disimilitud entre los individuos que se agrupan. Se identifican un total de 5 agrupaciones que contienen 55 de los 58 individuos con análisis completos (los individuos CR-5 y CR-30 en FRX sólo tie- nen preparaciones de perla), mientras que tres individuos quedan como mal clasificados a la derecha del dendrograma. Estas agrupaciones están influidas principalmente por las variaciones relativas de $\mathrm{CaO}$ y $\mathrm{Na}_{2} \mathrm{O}$. Las agrupaciones CRA1 y CRA2 engloban individuos con valores bajos de $\mathrm{Ln}(\mathrm{CaO} /$ $\mathrm{Al}_{2} \mathrm{O}_{3}$ ), presentando CRA1 valores también bajos de $\mathrm{Ln}\left(\mathrm{Na}_{2} \mathrm{O} / \mathrm{Al}_{2} \mathrm{O}_{3}\right)$, que son altos en la CRA2. Las 


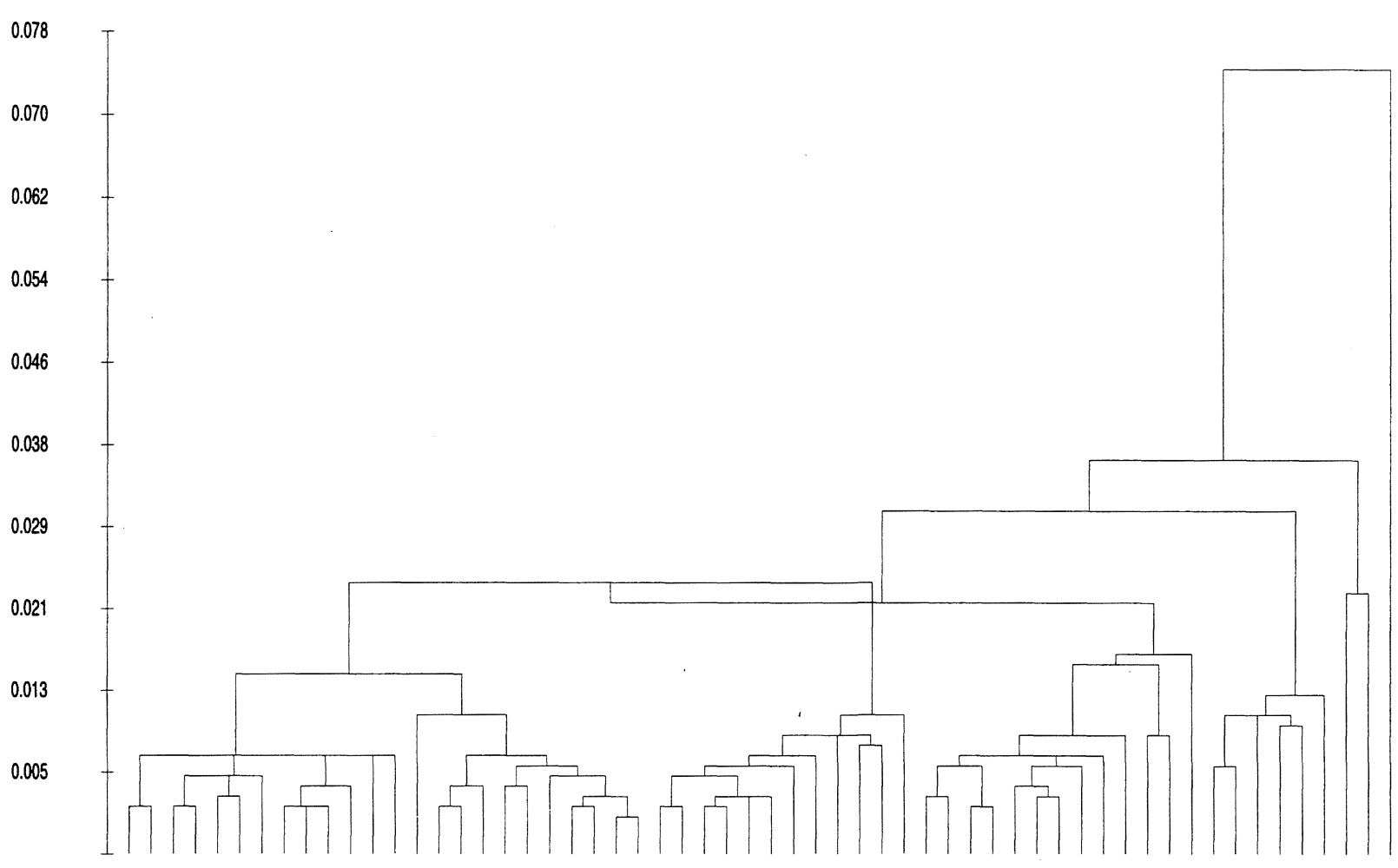

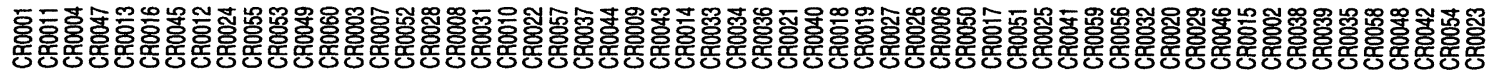 CRA1 CRB1 CRB3 CRB2 \\ CRA2}

Fig. 4. Dendrograma resultante del análisis de agrupamiento de los individuos analizados, realizado sobre la subcomposición $\mathrm{Fe}_{2} \mathrm{O}_{3}, \mathrm{MgO}, \mathrm{CaO}, \mathrm{Na}_{2} \mathrm{O}, \mathrm{K}_{2} \mathrm{O}, \mathrm{SiO}_{2}, \mathrm{Y}, \mathrm{Ce}$ y Ni , con el $\mathrm{Al}_{2} \mathrm{O}_{3}$ como divisor en la transformación de logaritmos de razón, empleando la distancia euclídea al cuadrado media y el algoritmo aglomerativo del centroide.

agrupaciones CRB1, CRB2 y CRB3 corresponden a individuos con valores más altos de $\mathrm{Ln}(\mathrm{CaO} /$ $\mathrm{Al}_{2} \mathrm{O}_{3}$ ), que en CRB3 alcanzan los valores máximos. La agrupación CRB2 ofrece además valores altos de $\mathrm{Ln}\left(\mathrm{Na}_{2} \mathrm{O} / \mathrm{Al}_{2} \mathrm{O}_{3}\right)$, a diferencia de CRB1 y CRB3. Los individuos CR-42, CR-54 y CR-23 quedan mal clasificados, aunque no tienen diferencias geoquímicas generales altamente significativas respecto a las composiciones observadas en las anteriores agrupaciones.

La principal dificultad para una correcta interpretación de estas agrupaciones es la práctica ausencia de grupos de referencia para la cerámica ática. Sin embargo, por encima de las diferencias observadas, destaca la fuerte similitud de todos los individuos estudiados, como puede apreciarse en la tabla 3. Esta similitud geoquímica sugiere una unidad composicional relacionable con un mismo ambiente geológico y permite plantear que todos los materiales analizados, incluyendo aquellos cuyas características físicas se alejan más de los parámetros definidos por el análisis tipológico-arqueológico del modelo de una cerámica ática, sean de la región del Ática, aunque puedan proceder de centros productores diversos. En este sentido, son de destacar los valores de $\mathrm{MgO}, \mathrm{CaO}$ y Ni, compatibles con los de esta zona, mostrando similitudes composicionales generales significativas (4) en la comparación de los resultados obtenidos con los alcanzados por Picon.

En el estudio mineralógico, la DRX permite identificar dos tendencias: por una parte los grupos CRA1, CRA2 y CRB1 y por otra los grupos CRB2

(4) Agradecemos profundamente al Dr. M. Picon el habernos facilitado la consulta de los datos analíticos inéditos del proyecto del Laboratoire de Céramologie (UPR 7524, CNRS, Lyon, Francia). 


\begin{tabular}{|l|l|l|l|l|}
\hline Elemento & Media & Desv.Est. & Valor mínimo & Valor máximo \\
\hline Fe2O3 & 8.5462 & 0.2868 & 7.8448 & 9.0343 \\
\hline $\mathbf{A 1 2 O 3}$ & 17.4536 & 0.6544 & 16.0784 & 18.4987 \\
\hline $\mathbf{M n O}$ & 0.1153 & 0.0151 & 0.092 & 0.1666 \\
\hline $\mathbf{P 2 O 5}{ }^{*}$ & $0.2511(0.2265)$ & $0.1908(0.0459)$ & $0.1327(0.1327)$ & $1.65(0.38)$ \\
\hline $\mathbf{T i O 2}$ & 0.9388 & 0.0394 & 0.8691 & 1.0919 \\
\hline $\mathbf{M g O}$ & 5.1335 & 0.442 & 4.3129 & 6.3748 \\
\hline $\mathbf{C a O}$ & 6.8214 & 1.5381 & 3.57 & 10.5146 \\
\hline $\mathbf{N a 2 O}$ & 0.8683 & 0.1984 & 0.5811 & 1.4599 \\
\hline $\mathbf{K 2 O}$ & 3.5627 & 0.2153 & 3.1322 & 4.0468 \\
\hline $\mathbf{S i O 2}$ & 56.1319 & 1.7268 & 52.0425 & 59.1532 \\
\hline $\mathbf{B a}{ }^{*}$ & $510(495)$ & $144(90)$ & $326(326)$ & $1364(747)$ \\
\hline $\mathbf{R b}$ & 134 & 9 & 115 & 150 \\
\hline $\mathbf{T h}$ & 14 & 1 & 12 & 17 \\
\hline $\mathbf{N b}$ & 14 & 1 & 13 & 16 \\
\hline $\mathbf{P b}{ }^{*}$ & $35(29)$ & $44(8)$ & $20(20)$ & $362(78)$ \\
\hline $\mathbf{Z r}$ & 139 & 9 & 120 & 157 \\
\hline $\mathbf{Y}$ & 25 & 2 & 20 & 28 \\
\hline $\mathbf{S r}$ & 217 & 46 & 121 & 332 \\
\hline $\mathbf{C e}$ & 58 & 8 & 34 & 78 \\
\hline $\mathbf{G a}$ & 20 & 2 & 16 & 23 \\
\hline $\mathbf{V}$ & 124 & 8 & 107 & 139 \\
\hline $\mathbf{Z n}$ & 115 & 9 & 10 & 139 \\
\hline $\mathbf{C u}$ & 53 & 20 & 25 & 151 \\
\hline $\mathbf{N i}$ & 314 & 26 & 264 & 366 \\
\hline
\end{tabular}

Tab. 3. Medias, desviaciones estándares, valores mínimos y máximos de los datos normalizados de los 58 individuos de Cancho Roano. Elementos mayores y menores en \% y elementos trazas en ppm $(*$ entre paréntesis los valores para 57 individuos excluyendo el individuo CR-26 que presenta alteraciones y contaminaciones en estos componentes).

y CRB3. Tecnológicamente, la agrupación CRB1 sigue un comportamiento similar al de las agrupaciones CRA1 y CRA2, mientras que las agrupaciones CRB 2 y CRB3, con contenidos relativos mayores de $\mathrm{CaO}$, se comportan durante la cocción como cerámicas claramente calcáreas (Maniatis et alii, 1981; Maniatis et alii, 1983).

El comportamiento mineralógico de las agrupaciones CRA1, CRA2 y CRB1 muestra dos rangos de temperatura de cocción equivalente (TCE) claramente diferentes, caracterizados por la cristalización de piroxenos en el rango inferior (TCE entre $850-900^{\circ} \mathrm{C}$ y $950-1000^{\circ} \mathrm{C}$ ) y por la descomposición de los picos de filosilicatos en el superior (TCE ligeramente superior a $950-1000^{\circ} \mathrm{C}$ ). La mayor parte de los individuos de estas agrupaciones se sitúan en el rango inferior de TCE (21 individuos), y pocos en el superior ( 9 individuos).

Igualmente se pueden establecer dos rangos de TCE en las agrupaciones CRB2 y CRB3 a partir de las mismas fases discutidas anteriormente y con TCE estimadas en los mismos intervalos. En estas agrupaciones, la mayor parte de individuos corresponden al rango inferior de TCE (13 individuos) y los menos al superior (11 individuos).
Así, la estimación de la TCE de los individuos analizados muestra una gran uniformidad, sin'grandes diferencias que puedan ser atribuidas a sobrecocciones severas o piezas crudas. Los rangos de TCE son coincidentes con los característicos de esta producción (Jones, 1986; Maniatis et alii, 1993).

Además de la temperatura de cocción, otro parámetro fundamental es la estructura de cocción oxidante-reductora-oxidante (Maniatis et alii, 1993) y las atmósferas bajo las cuales cristalizan las fases minerales. Entre los materiales analizados, las dificultades para controlar adecuadamente las atmósferas de cocción se reflejan en las variaciones cromáticas de barnices y matrices. Éstas se dan en individuos de todas las agrupaciones por igual, sin que ninguna de ellas represente una tecnología de producción inferior, comercializándose juntas piezas de acabados muy dispares.

Estas variaciones que presentan algunos individuos con respecto al modelo ideal de acabado de las cerámicas áticas de figuras rojas se deben a una multiplicidad de factores que interactúan y que son de difícil identificación, como las microatmósferas ocasionadas por el apilamiento durante la cocción. Esta superposición puede ser además de una importancia crítica cuando el barniz se impermeabiliza al oxígeno en la fase reductora y la única entrada de oxígeno a la fábrica es la zona no barnizada del fondo externo. Así, la zona alcanzada por la reoxidación a partir de este fondo puede depender de la situación relativa respecto éste. Asimismo, posibles accidentes o falta de control, especialmente en las dos últimas fases de la cocción, pueden producir coloraciones no esperadas (barnices rojos por una reducción demasiado corta, matrices oscuras por una reoxidación a una temperatura ya demasiado baja, etc.).

Un individuo excepcional es el CR-15 (agrupación CRB2), cuyo difractograma no muestra posibles fases de cocción, indicando una TCE inferior, como mínimo, a $800-850^{\circ} \mathrm{C}$, que explica el color de la fábrica (marrón claro) y el del barniz (marrón rojizo), así como el aspecto exfoliable de la fábrica.

Los individuos mal clasificados en la figura $4 \mathrm{y}$ los individuos con análisis químicos incompletos presentan comportamientos similares a los observados en las agrupaciones descritas anteriormente. Los individuos CR-42, 23 y 5 corresponderían a TCE del rango inferior $\left(850-900\right.$ a $\left.950-1000^{\circ} \mathrm{C}\right)$ de las agrupaciones no calcáreas, teniendo los dos pri- 
meros barnices de tonos pardos o rojizos. Los individuos CR-54 y 30, relacionables con las agrupaciones calcáreas, corresponderían a una TCE del rango inferior y superior respectivamente.

\section{CONCLUSIONES}

El estudio arqueométrico de las cerámicas áticas de Cancho Roano ha permitido definir diversas agrupaciones que, a pesar de sus diferencias, presentan una fuerte similitud geoquímica. Los datos disponibles sostienen como hipótesis un origen en el Ática para la totalidad de los materiales analizados. Tecnológicamente, existe una gran uniformidad en las temperaturas de cocción estimadas, situándose mayoritariamente entre $900-1000^{\circ} \mathrm{C}$. Todos los criterios de evaluación y validación apuntan contra la hipótesis de una posible producción peninsular o la presencia de productos fabricados en el Mediterráneo central. Sin embargo, la imposibilidad de referir los materiales estudiados a grupos de referencia de centros productores no permite una asignación definitiva de procedencia dentro del Ática, lo que imposibilita asegurar que las agrupaciones químicas definidas correspondan a diversos talleres o centros de producción.

La contrastación de estas agrupaciones químicas con la variabilidad tipológica y las características macroscópicas de fábricas y barnices muestra que no existe ninguna asociación clara entre tales agrupaciones y las diversas variantes tipológicas y diseños decorativos establecidas en el estudio arqueológico de Copa Cástulo (Tab. 4). Estas diferencias no responden a diversas áreas de producción. $\mathrm{La}$ tipología y las decoraciones obedecen a factores de variaciones entre talleres de una misma zona y no tiene por qué guardar una relación unívoca con un origen determinado. Por su parte, las variaciones en las características físicas obedecen principalmente a factores tecnológicos que invalidan las asignaciones de procedencia directa a partir de una observación macroscópica. La variabilidad formal y macroscópica que reflejan los materiales de Cancho Roano no resulta significativa.

La identificación clara de los talleres representados en Cancho Roano, así como la comprensión de los factores culturales que reflejan las variaciones formales, sólo será posible cuando exista un marco de conocimiento arqueométrico suficiente de los centros productores que permita una adecuada interpretación de las agrupaciones obtenidas

\begin{tabular}{|l|c|c|c|c|c|c|c|}
\hline & CRA1 & CRA2 & CRB1 & CRB2 & CRB3 & Mal clas & TOTAL \\
\hline CC 1B & 3 & 2 & 1 & 3 & 2 & 1 & $\mathbf{1 2}$ \\
\hline CC 1B/1C & 1 & & 1 & 1 & & & $\mathbf{3}$ \\
\hline CC 2A & & & & 3 & & & $\mathbf{3}$ \\
\hline CC 2B & & 1 & & & & & $\mathbf{1}$ \\
\hline CC 2C & 1 & 2 & 4 & 2 & 1 & & $\mathbf{1 0}$ \\
\hline CC 2D & 4 & & & 3 & 3 & 2 & $\mathbf{1 2}$ \\
\hline CC 2E & 1 & & & & 1 & & $\mathbf{2}$ \\
\hline CC 2F & & & & & 2 & & 2 \\
\hline CC 2F/2D-2H & & & 1 & & 1 & & $\mathbf{2}$ \\
\hline CC 2H & & & & & 1 & & $\mathbf{1}$ \\
\hline Fondo exterior & $\mathrm{B} 1$ & & $\mathrm{~B} 1, \mathrm{~N}-\mathrm{S}$ & $\mathrm{BI,P}, \hat{\mathrm{N}}$ & $\mathrm{F}, \hat{\mathrm{N}}, \mathrm{O}, \mathrm{P}$ & $\mathrm{B} 1$ & \\
\hline Delicate & 2 & 1 & 1 & & & & $\mathbf{4}$ \\
\hline Fig. Rojas & 1 & & & & & & $\mathbf{1}$ \\
\hline One handler & & & 1 & 1 & & & $\mathbf{2}$ \\
\hline Escifos & & & 2 & & 1 & & $\mathbf{3}$ \\
\hline TOTAL & $\mathbf{1 3}$ & $\mathbf{6}$ & $\mathbf{1 1}$ & $\mathbf{1 3}$ & $\mathbf{1 2}$ & $\mathbf{3}$ & $\mathbf{5 8}$ \\
\hline
\end{tabular}

Tab. 4. Distribución de los tipos estudiados en Cancho Roano según las agrupaciones composicionales resultantes. Mal clas = mal clasificados. $\mathrm{CC}=$ Copas Cástulo.

en este estudio y su correspondencia con los talleres originales.

Las implicaciones del estudio arqueométrico apuntan las siguientes conclusiones por lo que se refiere al proceso de formación y características del conjunto de vajilla fina ática del yacimiento. En primer lugar, la falta de análisis de los talleres de cerámica de barniz negro en el área del Ática impide establecer una seriación para la distribución de estos materiales en la Península Ibérica. Las características geoquímicas son suficientes para proponer una procedencia ática de los individuos, pero no para distinguir si los mismos corresponden al mismo lote cerámico (entendiendo con ello un solo momento de fabricación o un solo taller) o bien el hecho de que sean el resultado de un comercio progresivo y sostenido de vajilla ática hacia esta zona.

En segundo término, la diferencia en las características físicas de los individuos analizados indica que no existe una selección previa de los aspectos tipológicos ni macroscópicos de fábricas y barnices de los materiales distribuidos, por lo que no puede hablarse de una exigencia tipológico-estilística sino de una comercialización basada en la posesión y uso de un tipo cerámico concreto, obtenido y amortizado probablemente a partir de rituales de cohesión social. La diversidad y las deficiencias morfológicas de estas producciones indican asimismo que su valor en el área de producción es muy reducido, especialmente en relación con la cerámica ática de figuras rojas, mucho más controlada en sus parámetros de fabricación. Ello indicaría que se trata de una producción industrial destinada a mercados secundarios o bien a aquellos en los cuales la falta de 
competencia de tipos cerámicos de lujo hiciese posible una segura comercialización.

En tercer lugar, creemos que deben analizarse los conjuntos de cerámica griega peninsulares y del Mediterráneo central correspondientes a la segunda mitad del siglo $\mathrm{V}$ y primer cuarto del siglo IV a.C. a fin de precisar tanto las cronologías de las tipologías que los componen como las rutas y agentes comerciales.

Por último, consideramos que el tema de los análisis arqueométricos de la vajilla ática fina, y en especial de las Copa Cástulo, no debe considerarse como cerrado. La ampliación del espectro de los análisis a otros yacimientos peninsulares y extrapeninsulares, así como sobre todo la caracterización de los talleres en el área del Ática, debe permitir la definición de los grupos de producción y la seriación de la misma.

\section{BIBLIOGRAFÍA}

Aitchinson, J. (1986): The Statistical Analysis of Compositional Data. Chapman \& Hall. Londres.

- (1992): "On Criteria for Measures of Compositional Difference". Mathematical Geology, 24: 365-379.

Arribas, A.; Trías, G.; Cerdá, D. y de Hoz, J. (1987): El barco de El Sec (Calvià, Mallorca). Estudio de los materiales. Ajuntament de Calvià y Universitat de les Illes Balears. Palma de Mallorca.

BLONDÉ, F. (1985): "Un remblai thasien du IVème siècle avant notre ère". Bulletin de Correspondance Héllenique, CIX-I: 281-344.

- (1989): "La céramique". Bulletin de Correspondance Héllenique, CXIII, II: 489-519.

- (e.p.): "La céramique attique en Grèce du nord". La céramique attique du IVe siècle en Méditerranée occidentale (Arles, 1996). Ed. Centre Jean Bérard. Naples.

BuXEDA I GARRIGÓs, J. (1999): “Alteration and contamination of archaeological ceramics. The perturbation problem". Journal of Archaeological Sciences, 26: 295313.

- (e.p.): "Problemas en torno a la variación composicional". Monografías de Arte y Arqueología. Universidad de Granada. Granada.

Buxeda i Garrigós, J. y KiLIKoglou, V. (e.p.): "Total variation as a measure of variability in chemical data sets". En L. van Zelst (ed.): Patterns and Process. Smithsonian Institution. Washington D.C.

Buxeda i Garrigós, J.; Cau Ontiveros, M.A.; Gurt i EspaRraguera, J.M. y Tuset i Bertran, F. (1995): "Análisis tradicional y análisis arqueométrico en el estudio de las cerámicas comunes de época romana". En Ceràmica comuna romana d'època alto-imperial a la península Ibèrica. Estat de la qüestió. Monografies Emporita- nes, VIII. Conjunt Monumental d'Empúries. Empúries: 39-60.

Celestino, S. (1996): El Palacio-Santuario de Cancho Roano V-VI-VII. Los sectores oeste, sur y este. MAPB, Publicaciones, 3. Badajoz.

Celestino, S. y JimÉnez, F.J. (1993): El Palacio-Santuario de Cancho Roano IV -El Sector Norte-. Serie Arqueológica, 1. Badajoz.

Fillières, D.; Harbottle, G. y Sayre, E.V. (1983): "Neutron activation study of figurines, pottery and workshop materials from the AthenianAgora, Greece". Journal of Field Archaeology, 10: 55-69.

GARCía MARTín, J.M.(1997): "Les ceràmiques gregues". En M. Olcina (ed.): La Illeta dels Banyets (El Campello, Alicante). Estudios de la Edad del Bronce y Época Ibérica. Serie Mayor, 1. Museo Arqueológico Provincial de Alicante. Alicante: 175-206.

Gracia Alonso, F. (1994): "Las copas de Cástulo en la península Ibérica. Problemática y ensayo de clasificación". Huelva Arqueológica, XIII, 1: 175-200.

- (1997): Las cerámicas áticas del Palacio Santuario de Cancho-Roano (Zalamea de la Serena,Badajoz), Badajoz.

- (e.p.): "Importaciones de cerámicas áticas en el poblado ibérico de la Moleta del Remei (Tarragona). Problemática cronológica". La céramique attique du IVe siècle en Méditerranée occidentale (Arles, 1996). Ed. Centre Jean Bérard. Naples.

JONES, R.E. (1986): Greek and cypriot pottery. A review of scientific studies. British School at Athens, Fitch Laboratory Occasional Paper 1. Athens.

Maniatis, Y; Aloupi, E. y Stalios, A.D. (1993): "New evidence for the nature of the attic black gloss". Archaeometry, 35: 23-34.

Maniatis, Y.; Simopoulos, A. y Kostikas, A. (1981): "Moessbauer Study of the Effect of Calcium Content on Iron Oxide Transformations in Fired Clays". Journal of the American Ceramic Society, 64: 263-269.

Maniatis, Y.; Simopoulos, A.; Kostikas, A. y Perdikatsis, V. (1983): "Effect of Reducing Atmospheres on Minerals and Iron Oxides Developed in Fired Clays: the Role of Ca". Journal of the American Ceramic Society, 66: 773-781.

Mirti, P.; Casoli, A.; Barra Bagnasco, M. y Preacco AnCONA, M.C. (1995): "Fine ware from Locri Epizephiri: a provenence study by inductively coupled plasma emission espectroscopy". Archaeometry, 37: 41-51.

PiCON, M. (1989): "Notes sur les analyses de céramiques". Bulletin de Correspondance Héllenique, 113: 547-549.

Rotuno, T.; Sabbatini, L. y Corrente, M. (1997): “A provenance study of pottery from archaeological sites near Canosa, Puglia (Italy)". Archaeometry, 39: 343-354.

SPARKES, B. y TAlCOTT, L. (1970): Black and plain potery of the $6^{\text {th }} 5^{\text {th }}$ and $4^{\text {th }}$ centuries B.C. The Athenian Agora, Volume XII. The American School of Classical Studies at Athens. Princenton, New Jersey. 
SÁNCHEZ, C. (1981): "La cerámica ática de Ibiza en el Museo Arqueológico Nacional". Trabajos de Prehistoria, 38: 281-308.

- (1992): "Las copas tipo Cástulo en la península Ibérica". Trabajos de Prehistoria, 42: 327-333.
WolfF, S.R.; Liddy, D.J.; Newton, G.W.A.; Robinson, V.J. y Sмith, R.J. (1986): "Classical and Hellenistic Black Glaze Ware in the Mediterranean: A Study by Epithermal Neutron Activation Analysis". Journal of Archaeological Science, 13: 245-259.

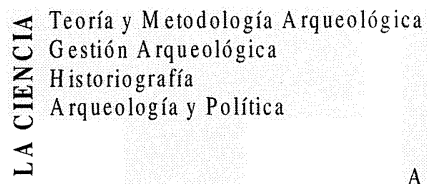

A rqueología Prehistórica y Protohistórica Paleolítico

Neolítico

Calcolítico

Edad del Bronc

Edad del Hierro

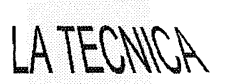

Datación absoluta

Arqueología analítica

Arqueom etalurgia

Tecnología experimental
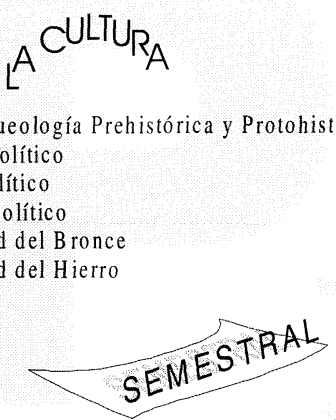

Trabajos de Prehistoria es la revista de consulta imprescindible para todos aquellos interesados en conocer el estado de la cuestión sobre el rico patrimonio arqueológico de la Prehistoria y Protohistoria de la Península lbérica. Sus páginas reflejan tendencias punteras de su especialidad, por lo que figura en los más significativos repertorios bibliográficos nacionales e

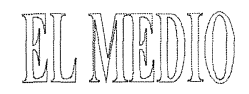

Arqueobotánica Arqueozoología Arqueología del Paisaje internacionales.

\section{BOLETIN DE PEDIDO

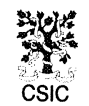 \\ Servicio de Publicaciones \\ Teléfono:91/561 2833 Fax: $91 / 5629634$ Vitruvio, $8 \cdot 28006$ Madrid (España) \\ Nombre \\ Dirección \\ Ciudad}

TRABAJOS DE PREHISTORIA

(Revista Semestral)

\footnotetext{
Adjunto cheque bancario por valor de ............Ptas. a nombre de Servicio de Publicaciones CSIC

Contra reembolso

Envíenme, por favor, factura pro-forma

$\square$ Tarjeta $\mathrm{Visa} / 4 \mathrm{~b} / \mathrm{M}$ astercard/M aestro

Número Fecha de caducidad
}

Suscripción anual

Fecha.

Firma

\section{N. sueltos}

Suscripción España: 5600 Ptas. Suscripción Extranjero: 8200 Ptas.

$\mathrm{N}^{0}$ suelto España: 3300 Ptas.

$\mathrm{N}^{\circ}$ suelto Extranjero: 5000 Ptas.

T. P., 56, n. ${ }^{\circ} 1,1999$ 